\title{
Management of the pharmacological treatment in patients with chronic obstructive pulmonary disease
}

Gestão do regime farmacológico em doentes com doença pulmonar obstrutiva crónica Gestión del régimen farmacológico en pacientes con enfermedad pulmonar obstructiva crónica

\author{
Celeste Bastos*iD; Sílvia Vieira**iD; Lígia Lima***(D)
}

\section{Abstract}

Background: Chronic obstructive pulmonary disease (COPD) is a chronic and incapacitating disease, whose regimen includes inhalation medication. The evidence shows a low adherence, which may increase the aggravation of the disease.

Objectives: To study the adherence and the perceived competence of patients to comply with the treatment regimen of COPD and evaluate their knowledge on the use of inhalers.

Methodology: Quantitative and cross-sectional study, participants were 45 patients with COPD. We used the Medication Adherence Rating Scale (MARS), the Perceived Competence Scale (PCS), and a questionnaire on the use of inhalers.

Results: Participants reported good adherence to the medication regimen and reported a high degree of perceived competence to maintain the treatment regimen of COPD. However, they manifested little knowledge about the use of inhalers and the inhalation technique, which compromises the effectiveness of the established therapeutic plans and exacerbate the deterioration of the clinical condition.

Conclusion: This study suggests that nursing care should be developed with a focus on knowledge and training in the inhalation technique.

Keywords: pulmonary disease, chronic obstructive; medication adherence; perceived competence; inhalers

\section{Resumo}

Enquadramento: A doença pulmonar obstrutiva crónica (DPOC) é uma doença crónica e incapacitante, cujo regime terapêutico inclui medicaçáo por via inalatória. A evidência revela uma baixa adesão terapêutica, o que pode potenciar o agravamento da doença.

Objetivos: Estudar a adesão e a competência percebida das pessoas para cumprirem o regime de tratamento da DPOC e avaliar o seu conhecimento sobre o uso de inaladores.

Metodologia: Estudo quantitativo e transversal. Participaram 45 pessoas com DPOC. Utilizou-se a Escala de Adesáo aos Medicamentos, a Escala de Competência Percebida e um questionário sobre o uso de inaladores. Resultados: Os participantes relataram uma boa adesão ao regime medicamentoso e reportaram um elevado grau de perceção de competência para manter o regime de tratamento da DPOC. No entanto, revelaram poucos conhecimentos sobre o uso dos inaladores e a técnica inalatória, o que compromete a eficácia dos planos terapêuticos instituídos e potenciam o agravamento da condição clínica.

Conclusáo: Este estudo sugere que sejam desenvolvidos cuidados de enfermagem centrados nos conhecimentos e no treino da técnica inalatória.

Palavras-chave: doença pulmonar obstrutiva crónica; adesão à medicação; competência percebida; inaladores

*Ph.D., Adjunct Professor, Nursing School of Porto, Rua Dr. António Bernardino de Almeida 4200-072, Porto, Portugal [chastos@esenfpt]. (10 https://orcid.org/0000-0001-5907-6702. Contribution to the article: bibliographical research; statistical treatment and assessment; data analysis and discussion; writing of the article. Address for correspondence: Rua Dr. António Bernardino de Almeida, 4200-072, Porto, Portugal.

**MSc., NR, Hospital Center of Tâmega e Sousa, E.P.E., Avenida do Hospital Padre Américo, 210, 4564-007, Penafiel, Portugal [silvia vieira3@hotmail.com]. (10 https://orcid.org/00000003-2650-1455. Contribution to the article: bibliographical research; data collection; data analysis and discussion.

***:Ph.D., Coordinating Professor, Nursing School of Porto, Rua Dr. António Bernardino de Almeida, 4200-072, Porto, Portugal [ligia@esenf.pt].(1) https://orcid.org/0000-0003-4556-0485. Contribution to the article: statistical treatment and assessment; data analysis and discussion; writing of the article.

\section{Resumen}

Marco contextual: La enfermedad pulmonar obstructiva crónica (EPOC) es una enfermedad crónica e incapacitante cuyo régimen terapéutico incluye medicación por vía inhalatoria. La evidencia muestra una baja adhesión terapéutica, lo que puede potenciar el empeoramiento de la enfermedad.

Objetivos: Estudiar la adhesión y la competencia percibida de las personas para que cumplan el régimen de tratamiento de la EPOC y evaluar su conocimiento sobre el uso de inhaladores.

Metodología: Estudio cuantitativo y transversal en el que participaron 45 personas con EPOC. Se utilizó la Escala de Adhesión a los Medicamentos, la Escala de Competencia Percibida y un cuestionario sobre el uso de inhaladores.

Resultados: Los participantes indicaron una buena adhesión al régimen de medicamentos y un elevado grado de percepción de la competencia para mantener el régimen de tratamiento de la EPOC. Sin embargo, mostraron pocos conocimientos sobre el uso de inhaladores y la técnica inhalatoria, lo que compromete la eficacia de los planes terapéuticos instituidos y potencia el empeoramiento del estado clínico.

Conclusión: Este estudio sugiere que se desarrollen cuidados de enfermería centrados en los conocimientos y en el entrenamiento de la técnica inhalatoria.

Palabras clave: enfermedad pulmonar obstructiva crónica; cumplimiento de la medicación; competencia percibida; inhaladores 


\section{Introduction}

The chronic obstructive pulmonary disease (COPD) represents a significant challenge for public health because, according to the Global Initiative for Chronic Obstructive Lung Disease (GOLD, 2018), it is the fourth cause of worldwide mortality and causes high morbidity. In Portugal, a study conducted in the metropolitan area of Lisbon estimated the prevalence of the disease of $14.2 \%$ in individuals with 40 or more years old (Bárbara et al., 2013).

COPD is a complex and progressive disease, with a substantial impact in society and healthcare (GOLD, 2018), and has high economic costs, because the therapeutic regimen is complex and expensive. There is a need for regular healthcare, as well as frequent hospitalizations due to worsening of the clinical situation.

The treatment regimen of COPD includes non-pharmacological therapies (nutrition, physical exercise, smoking cessation, respiratory rehabilitation, among others) and pharmacological therapies (bronchodilators, anti-inflammatory drugs, mucolytics, among others; GOLD, 2018). The administration of drugs by inhalation is the preferred and most recommended route in the symptomatic pharmacological treatment of COPD since it acts directly on the airways and is associated with a lower incidence of side effects (GOLD, 2018). However, the repertoire of knowledge and skills required in this type of therapy is considered complex, given the multiplicity of drugs, the existence of different devices, and the specificities in their handling and application (Price et al., 2018), aspects that contribute to hinder its correct use.

Several studies mention a low adherence to inhalation therapy and the incorrect use of inhalers by patients with COPD (Melani \& Paleari, 2016; Sriram \& Percival, 2016). There is also evidence that the non-adherence or the errors in the inhalation technique can compromise the control of symptoms and exarcebate the worsening of the clinical situation (Bryant, Bang, Chew, Baik, \& Wiseman, 2013; Melani \& Paleari, 2016; Price et al., 2018).

Perceived competence is a motivational variable that has been identified as a predictive factor of health-promoting behaviors (Almeida, 2013), namely of adherence to the therapeutic regimen (Rocha, 2017).
Currently, according to GOLD (2018), COPD is a common, preventable, and treatable disease. Therefore, a study should be conducted with the purpose of developing knowledge about how a patients with COPD manages the pharmacological regimen.

This study aimed to assess the level of adherence and the perceived competence of patients to comply with the treatment regimen of COPD and to explore the relation between these two variables. Its purpose was also to examine the knowledge of patients with COPD on the use of inhalers.

\section{Background}

COPD is a disease characterized by long-term breathing problems (dyspnea, chronic cough, and bronchial hypersecretion) and progressively low airflow, due to alveolar and airway changes. The main risk factor for the development of the disease is the exposure to harmful particles and gases (GOLD, 2018).

Because of his/her chronic condition, the patient with COPD faces multiple demands, from the experience of debilitating symptoms (Jácome, Marques, Gabriel, Cruz, \& Figueiredo, 2015) to the complex therapeutic regimen (GOLD, 2018), in its pharmacological and non-pharmacological diversity.

The literature identifies the complexity of the therapeutic regimen as one of the factors hindering the adherence to treatment, for example, in post-renal transplantation patients (Gonçalves, Reveles, Martins, Rodrigues, \& Rodrigues, 2016) and patients with COPD (Blackstock, ZuWallack, Nici, \& Lareau, 2016). Inhalation therapy is one of the essential recommendations of the pharmacological regimen in COPD, which requires mastery in handling inhalers (Aguiar et al., 2017; Melani \& Paleari, 2016; Pothirat et al., 2015). It is, therefore, imperative that the patient with COPD receives support from health professionals to become more aware of the advantages of pharmacological adherence and to acquire competence in the self-administration of medication (Aguiar et al., 2017; Price et al., 2018). Thus, the patients can ensure better control of the disease and its repercussions in his/her life. This process is called self-management (Lorig \& Holman, 2003). There are several indicators of a process of 
self-management in literature. In this study, we selected the following indicators: therapeutic adherence, perceived competence, and knowledge about the pharmacological regimen (use of inhalers).

The therapeutic adherence implies assessing to which degree the person complies with the pharmacological and non-pharmacological treatment. As regards the pharmacological treatment, it describes the behavior about the prescribed regimen, particularly if the person complies with the guidelines given by the healthcare professional who prescribed it or to which extent he/she adjusts or alters the prescribed dosages (Pereira \& Silva, 1999).

The perceived competence, a concept similar to self-efficacy, is described as the perception the person has of his/her ability to initiate and maintain a specific behavior which favors his/her health (Almeida, 2013; Rocha, 2017), for example, to comply with the treatment regimen of COPD. The acquisition of knowledge about inhalation devices and the administration technique of different drugs is essential to ensure treatment adherence in COPD and mastery in the application of inhalers (Price et al., 2018).

Several medicines are administered via inhalation, so the combination of drugs with different action mechanisms and schedules can be pertinent, to simplify the dosage regimen and reduce the effects (GOLD, 2018).

There are four main types of devices for applying the drug by inhalation: the pressurized metered dose inhaler - MDI, the dry powder inhaler - DPI, the soft mist inhaler - SMI, and also the nebulizers (Aguiar et al., 2017). Each device has specific instructions, and all require a previous explanation about their use, meaning that individualized training is relevant to empower the user for a correct administration (GOLD, 2018). In the article by Aguiar et al. (2017), information is provided about the different inhalers and their inhalation technique. There are common aspects in the use of the devices, namely: it is essential to make a forced expiration, prior to inhalation, to empty all the air contained in the lungs; after inhalation one should perform a respiratory pause for about 10 seconds, to ensure drug penetration in the airways; after the administration of corticosteroids one should wash the oral cavity without swallowing water; and one should ensure the sanitization of the inhalation device.

The correct use of inhaler is of the utmost importance to ensure the efficient administration of the prescribed drug (Bryant et al., 2013; Pothirat et al., 2015; Sriram \& Percival, 2016). In a study by Molimard and Colthorpe (2015), patients with COPD mentioned that the devices they preferred and found more easy to use, were those which had fewer handling steps, were activated by breathing and confirmed drug delivery. In another study, patients were instructed about the inhalation technique by health professionals and felt confident about the application of the inhaler and the correct dosage, whereas the patients with no instruction felt insecure about the dosage and repeated the application with the risk of overdosage (Price et al., 2018).

There is evidence of incorrect use of inhalers by patients (Bryant et al., 2013; Melani \& Paleari, 2016; Pothirat et al., 2015; Sriram \& Percival, 2016) and there is often a low adherence to inhalation treatment (Pothirat et al., 2015).

There are several errors identified in the implementation of the inhalation technique, namely: wrong inspiratory flow; non-compliance with the time of inhalation; poor coordination between inhalation and administration; errors in the preparation of the dosage, in forced expiration before inhalation, and in suspension of breathing during inhalation (GOLD, 2018). The incorrect use of inhalers is associated to the aggravation of symptoms and of the clinical condition (Melani \& Paleari, 2016; Riley \& Krüger, 2017). However, the demonstration of the inhalation technique by health professionals, followed by training by patients, proved to be effective in acquiring skills for the self-administration of inhalers (Hickey et al., 2017; Price et al., 2018). Furthermore, the execution of the technique should be regularly evaluated to ensure mastery over time (Azzi, Srour, Armour, Rand, \& Bosnic-Anticevich, 2017).

\section{Research Questions}

To which extent do patients with COPD adhere to the drug regimen?

To which extent do patients feel competent of following the treatment of COPD? 
What is the type of relationship between drug adherence and perceived competence to comply with the treatment regimen of COPD?

What knowledge do patients with COPD have on the use of inhalers?

\section{Methodology}

We conducted a descriptive and cross-sectional study. The population in this study were patients with a COPD diagnosis, residing in a region of northern Portugal. We assembled a convenience sample of 45 patients hospitalized in the department of internal medicine at a hospital institution in the district of Porto, from 10 February to 10 May 2017. To select the participants, we used the following inclusion criteria: a) medical diagnosis of COPD; b) worsened respiratory function as reason for hospitalization; c) 18 years of age or older; d) no identified cognitive deficits; e) accepting to participate in the study, in a voluntary and informed way.

The study was carried out with hospitalized patients, since there is no specific outpatient clinic for patients with COPD in this region of the country. Nevertheless, the assessment of the adherence, the perceived competence, and the knowledge about the use of inhalers concerns the context of patient's daily life before hospitalization". We must emphasize that, during hospitalization, the medication that the patient took at home as instructed was replaced by hospital medication, which health professionals managed and administered.

For the collection of data we used a questionnaire the patients with the assistance of the researcher, which included the following instruments: a) Sociodemographic and health questionnaire; b) Medication Adherence Rating Scale (MARS) adapted to the Portuguese population by Pereira and Silva (1999), composed of four items subdivided into two groups, in a Likert-type scale of five points, whose final evaluation is obtained through the sum of the four items, the scores ranging between 4 and 20, and the higher values corresponding to higher levels of adherence; c) Perceived Competence Scale (PCS), adapted to the Portuguese population by Almeida (2013), which is composed of four items in a Likert-type scale which goes from 1 (not true) to 7 (entirely true), whose result is obtained through the mean of response to the 4 items, in which the higher the value, the more competent the person feels to follow the behavior in evaluation; d) Questionnaire on the use of inhalers and assessment of knowledge about the inhalation technique, formulated for this study, which included questions about the number of inhalers used and their identification by the patients, instructions received on the use of inhalers and supervision of the inhalation technique and, also, an open question to describe the inhalation technique freely. There was no self-administration of inhalers because this therapy was not prescribed during hospitalization and there were no available devices to simulate the inhalation technique.

The data collection occurred during the hospital stay, and the ethical requirements were complied with, in particular, the authorization of the study by the institution's Ethics Committee and the informed and voluntary consent by the participants in the study.

\section{Results}

Most of the participants were male $(86.7 \%)$, and only six participants were female $(13.3 \%)$, aged between 46 and 87 years old $(M=70.9$; $S D=11.9)$. Concerning the civil status, the majority of participants $(73.3 \%)$ were married or lived in non-marital partnership. The participants had an average of 4.4 years of schooling $(S D=2.2$ years), with a minimum of one year of schooling and a maximum of 16 years of schooling. As regards the professional situation, the majority was retired $(75.6 \%)$ and only eight participants were employed. The COPD diagnosis of the majority of participants neither was confirmed by spirometry nor obeyed the GOLD classification.

The participants showed values of medication adherence slightly above the average level (Table 1), which means a good adherence to prescribed medication. Regarding perceived competence, the average of $5.2(S D=1.6)$ represents a high degree of perceived competence (Table 1), that is, the participants feel confident in their ability to maintain the treatment regimen of COPD. 
Table 1

Descriptive measures relating to medication adherence and perceived competence

\begin{tabular}{lcccc}
\hline & Min. & Max. & $M$ & $S D$ \\
\hline Medication Adherence Rating Scale & 4 & 20 & 12.5 & 4.4 \\
\hline Perceived Competence Scale & 1 & 7 & 5.2 & 1.6 \\
\hline
\end{tabular}

Note . Min. = Minimum; Max. = Maximum; $M=$ Mean; $S D=$ Standard deviation.

In order to determine the strength and direction of the link between the variables medication adherence and perceived competence, we applied Pearson's correlation coefficient $(r)$. The result of the correlation was high and very significant $(r=0.68 ; p=0.0001$; Pallant, 2010), which means that the participants who reported higher levels of adherence were those who perceived themselves as abler to manage the treatment regimen of COPD.

Concerning the inhalation therapy, 32 participants use inhalers $(71.1 \%)$, whereas the remaining 13 participants $(28.9 \%)$ are not medicated with inhalation therapy. The participants with inhalation medication have been complying with this therapy, on average, for 4.2 years $(S D=3)$. The majority of participants were medicated with two inhalers (53.1\%), and 21 participants $(65.6 \%)$ identified all the inhalers, but six participants $(18.8 \%)$ failed to identify any of the inhalers. All participants generally agree that the inhalers are easy to use $(100 \%)$ and also find they perform the technique correctly $(100 \%)$, even participants who do not have identified the inhalers they applied. The first teaching in $90.6 \%$ of cases was about the responsibility of the physician, and regarding the supervision of the self-administration of the inhalers, only ten of the persons (37\%) were supervised by a health professional. The majority of participants $(93.8 \%)$ manifested no interest in receiving another type of support in the use of inhalers, and only two participants $(6.3 \%)$ manifested interest in receiving written information.

The application of inhalers is a complicated technique, given the multiplicity of drugs, the existence of different types of inhalers, and the specificities in their application. In order to ascertain whether the self-administration of inhalers was performed correctly, we introduced an open question where we asked participants to describe the inhalation technique used at home because patients were medicated with inhalers during hospitalization and it was not possible to use simulation devices to study the self-administration. The analysis of the responses' content revealed a knowledge gap related to the inhalation technique in virtually all participants ( 30 out of a total of 32 people), mostly related to "do not perform forced expiration before inhalation" and "do not hold your breath for approximately 10 seconds after inhalation." Only one participant said that he/ she performed oral hygiene after the application of the inhaler and none of the participants disinfected the inhaler after inhalation.

\section{Discussion}

In this study, conducted with patients admitted in hospital medicine units, due to their worsened chronic condition of COPD, the majority of participants are men, with a mean age of 70.9 years old, retired, married, and with low schooling. The characteristics listed here are similar to other studies, conducted in Portugal, on patients with COPD, exemplified by the study of Jácome et al. (2015). A significant number of patients was medicated with inhalation therapy at home, but it was not possible to ascertain the severity of the clinical condition since there were no records with the staging of the disease according to the GOLD classification. It is also worth mentioning that, in most cases, the clinical diagnosis was not confirmed by spirometry, as recommended by GOLD guidelines (2018).

As regards medication adherence, the participants are slightly above the mean level of adherence, but we must highlight that the used questionnaire refers to the adherence to drugs and not just the inhalation therapy. Maybe this is why the results of this study differ from the evidence that adherence tends to be low 
when the therapeutic regimen is complex (Gonçalves et al., 2016), specifically in patients with COPD undergoing inhalation therapy (Melani \& Paleari, 2016; Sriram \& Percival, 2016). A unique feature of the disease, which may explain the values of adherence found, is the constant presence of uncomfortable and even incapacitating symptoms, which can be both a warning and a reinforcement for taking the medication. It is also important to note that the study population was mostly elderly and, according to the study of Price et al. (2018), adherence is higher in older people than in younger people.

Concerning the perceived competence, the results showed that the participants feel highly confident in their ability to maintain the treatment regimen of COPD. As there are no previous studies with patients with COPD that allow comparing results, we discuss ours, using studies with another type of chronic pathologies. Interestingly, the results obtained in patients with heart problems (Rocha, 2017) show a similar trend. Moreover, it is necessary to note that the occurrence of this outcome may be associated with the psychometric properties of the instrument, suggesting that it is not sufficiently discriminating and promotes a ceiling effecteffect on results. Also, the participants, when assessing their competence, may not possess a substantial and realistic knowledge base and, thus, tend to overestimate their capabilities. We found a strong association between medication adherence and perceived competence, that is, the participants who reported higher levels of medication adherence were those who perceived themselves as more competent to manage their therapeutic regimen. This result agrees with the latest evidence within the context of the processes of self-management in chronic disease, which highlights the role of perceived competence in the processes of disease management. The study by Rocha (2017) stands out in this context, the perceived competence revealing to be a good predictor of smoking abstinence after hospital discharge in patients who have suffered acute coronary syndrome.

In relation to the use of inhalers, 32 participants reported the use of these devices, mostly two inhalers, on average time of 4.2 years, which confirms the relevance of inhalation therapy in the treatment of COPD (Aguiar et al., 2017; Pothirat et al., 2015) and the need, mentioned in the literature, to combine more than one drug or device (GOLD, 2018). However, 11 of the 32 participants cannot correctly identify all the devices they use. This lack of knowledge about the prescribed inhalers can be a hindering factor for the correct application of the drug. For instance, Molimard and Colthorpe (2015) reported that the use of multiple inhalers reduces adherence.

All participants consider the inhalation technique is easy to perform and report they perform it correctly. Perhaps this is why only two of the 32 people showed interest in receiving more support on the use of inhalers. However, we reiterate that the implementation of the inhalation technique was not observed directly, as the participants were asked only about the difficulty degree and their performance, which restricts the interpretation of this result.

Different studies state that the inhaler's correct use is critical to administer therapy effectively and, thus, to ensure the control of symptoms and the prevention of disease exacerbations (Bryant et al., 2013; Melani \& Paleari, 2016; Pothirat et al., 2015). In our study, although the participants feel competent to comply with the prescribed treatment, when reporting the steps on the use of inhalers, only two patients demonstrated complete knowledge about the inhalation technique and the rest of the participants presented errors in more than one of the steps. In other words, the effectiveness of the inhalers is low in the overwhelming majority of the participants, as shown by multiple studies (Bryant et al., 2013; Price et al., 2018; Riley \& Krüger, 2017). We should remark that one of the participants who reported the technique more correctly had the highest level of schooling.

As the sample was composed mainly of participants with a low level of schooling and a mean age of approximately 70 years old, we believe that these factors may associate, at least partly, with the lack of knowledge about the correct application of the inhalers. The advanced age is considered a determinant factor of errors in the inhalation technique (GOLD, 2018). The vast majority of participants received training on the inhalation technique by the physician and felt very satisfied (13 patients or 
satisfied (19 patients) with the process of education. We verify that other studies identified the physician as the professional who more often assumes the responsibility for the first training of the inhalation technique (Bryant et al., 2013). The study by Azzi et al. (2017) highlights the importance of the initial intervention to obtain mastery, although, according to the authors, the primary education does not guarantee, by itself, that this mastery is maintained over time. Another study states that, following the training of the inhalation technique, regardless of the educational strategy, the individuals were able to use the inhalers correctly in the short term, but could not maintain the mastery over time for all devices (Hickey et al., 2017).

In this study, mostly friends and families observed the execution of the technique, possibly because of the daily contact with the patient at the time of the administration of inhaled medication, and the majority received no correction to their use. The lack of knowledge by the family and friends on the inhalation technique may be one of the reasons why no corrections were made. The results of this study do not meet the international recommendations which advise that health professionals provide the training and supervise the inhalation technique regularly (GOLD, 2018). Other results reflecting this gap in education and supervision occurred in the studies by Pothirat et al. (2015) and by Bryant et al. (2013).

We must emphasize that some studies reinforce the importance of regular supervision of the administration of inhalers, mainly because patients being supervised in the application of inhalers by health professionals manifested greater adherence than patients who were not supervised (Price et al., 2018). Other studies also revealed that a significant number of patients who mastered the inhalation technique at an early stage could not keep this mastery in subsequent assessments (Azzi et al., 2017; Hickey et al., 2017).

When studying the associations between variables, we detected a disparity between the confidence that the participants perceived about their ability to comply with the treatment and the manifestation of knowledge about the inhalation technique, which is fundamental to ensure the correct administration of the drugs. The results obtained by the application of the
PCS and MARS do not reflect the participants' knowledge gaps about the inhalers and inhalation technique, which we identified through the responses to the questionnaire. Nevertheless, if the majority of the participants were not supervised by a health professional at the time of self-administration of the inhaler, one expects that they are convinced of their mastery in the inhalation technique because they have not faced instructions contrary to their performance.

Thus, despite the high levels of perceived competence and medication adherence reported by the participants, some aspects of the therapeutic regimen may be compromised and can contribute to the deteriorated health condition of the participants. Moreover, the study participants were hospitalized due to the aggravation of their pathology and, in the literature, several studies alert to the relation between errors in the inhalation technique and the exacerbated symptoms (Bryant et al., 2013; Melani \& Paleari, 2016; Price et al., 2018).

The knowledge gap of the participants may relate to the lack of a follow-up appointment, which would allow the patient to receive feedback on the self-administration and eventually be corrected in the implementation of the inhalation technique by health professionals, as recommended by several recommendations and studies (Azzi et al., 2017; Blackstock et al., 2016; GOLD, 2018).

The interpretation of this study's results must take into account the fact that the study has some limitations. From the outset, the small number of participants and the inability to form groups with representativeness, in particular in relation to gender and schooling, did not allow exploring the possible influence of these variables. The fact that COPD is not staged in the majority of participants also limited the study of the relations between the clinical variables, the sociodemographic variables, and the main variables of the study. We should also highlight a possible bias resulting from how the data were collected, as, although we chose a questionnaire filled in with the assistance of the researcher to ensure fidelity, taking into account the participants' sociodemographic characteristics, the presence of the researcher may have caused some degree of social desirability. Finally, as it was mentioned earlier, the strategy to collect 
data relating to the administration of the inhaler was self-report and not observation, which may, therefore, have introduced some bias in the results. As a suggestion for future research and with the purpose of better understanding the difficulties of patients in the use of inhalers, it would be interesting to perform an observation of the self-administration of inhalation therapy.

\section{Conclusion}

Among the results of this study, we emphasize the perception of competence to maintain the treatment regimen of COPD and the perception of goodt adherence to the medication regimen. However, at the same time, the participants were hospitalized due to their worsened clinical condition, and we identified knowledge deficits about the inhalers and the inhalation technique. Therefore, these results reflect less positive aspects that need a planned and urgent intervention because of their possible implications in the control of symptoms and the worsening of the clinical condition of people with COPD.

The perception of competence is an important aspect, as it constitutes a motivating factor for self-management of the disease. However, it does not ensure, by itself, competent management. As it highlights the disparity between the results, this study shows the need to work other aspects related to the therapeutic adherence with the patients, so they can develop more realistic perceptions of their behaviors of management of the disease and be able to identify their needs and weaknesses in what concerns the acquisition of knowledge and skills.

The little knowledge that participants demonstrate about the use of inhalers and the inhalation technique compromises the effectiveness of the traditional therapeutic plans and exacerbate the deterioration of the clinical condition. In this respect, there are emerging needs for nursing care focused on knowledge and training in the inhalation technique.

The results of this study allow improving the knowledge on the process of self-management of the person with COPD and guiding a nursing practice that promotes the autonomy of people, enabling them to manage their disease and therapeutic regimen better.

\section{References}

Aguiar, R., Lopes, A., Ornelas, C., Ferreira, R., Caiado, J., Mendes, A., \& Pereira-Barbosa, M. (2017). Terapêutica inalatória: Técnicas de inalação e dispositivos inalatórios. Revista Portuguesa de Imunoalergologia, 25(1), 9-26. Retrieved from https://www.spaic.pt/ client_files/rpia_artigos/teraputica-inalatria-tcnicas-de-inalao-e-dispositivos-inalatrios.pdf

Almeida, M. C. (2013). Motivação e comportamento de saúde, relação com a qualidade de vida, em adultos da comunidade (Ph.D. Thesis). Faculdade de Psicologia e de Ciências da Educação da Universidade do Porto, Portugal.

Azzi, E., Srour, P., Armour, C., Rand, C., \& Bosnic-Anticevich, S. (2017). Practice makes perfect: Self-reported adherence a positive marker of inhaler technique maintenance. NPJ Primary Care Respiratory Medicine, 27(1), 29. doi:10.1038/s41533-017-0031-0

Bárbara, C., Rodrigues, F., Dias, H., Cardoso, J., Almeida, J., Matos, M. J., ... Burney, P. (2013). Chronic obstructive pulmonary disease prevalence in Lisbon, Portugal: The burden of obstructive lung disease study. Revista Portuguesa De Pneumologia, 19(3), 96-105. doi:10.1016/j.rppneu.2012.11.004

Blackstock, F. C., ZuWallack, R., Nici, L., \& Lareau, S. C. (2016). Why don't our patients with chronic obstructive pulmonary disease listen to us? The enigma of nonadherence. Annals Of The American Thoracic Society, 13(3), 317-323. doi:10.1513/AnnalsATS.201509-600PS

Bryant, L., Bang, C., Chew, C., Baik, S. H., \& Wiseman, D. (2013). Adequacy of inhaler technique used by people with asthma or chronic obstructive pulmonary disease. Journal of Primary Health Care, 5(3), 191198. doi:10.1071/HC13191

Gonçalves, P. R., Reveles, A., Martins, H. I., Rodrigues, I. L., \& Rodrigues, S. M. (2016). Adherence to immunosuppressive therapy in kidney transplant recipients: Integrative literature review. Revista de Enfermagem Referência, 4(8), 121-130. doi:10.12707/RIV14063

Global Initiative for Chronic Obstructive Lung Disease. (2018). Global strategy for the diagnosis, management, and prevention of chronic obstructive pulmonary disease. Retrieved from https:/goldcopd.org/wp-content/ uploads/2017/11/GOLD-2018-v6.0-FINAL-revised20-Nov_WMS.pdf

Hickey, S., Beeson, P., Furniss, S., Mulligan-Evans, F., Ryan, E., \& Keech, J. (2017). The effect of structured education on inhaler technique. Practice Nursing, 28(5), 196-206. doi:10.12968/pnur.2017.28.5.196

Jácome, C., Marques, A., Gabriel, R., Cruz, J., \& Figueiredo, D. (2015). Anxiety and depression in Portuguese 
patients with chronic obstructive pulmonary disease: A multicentre cross-sectional study. Revista Portuguesa de Medicina Geral e Familiar, 31(1), 24-32. Retrieved from http://www.scielo.mec.pt/pdf/rpmgf/v31n1/ v31n1a04.pdf

Lorig, K. R., \& Holman, H. R. (2003). Self-management education: History, definition, outcomes, and mechanisms. Annals Of Behavioral Medicine, 26(1), 1-7. doi:10.1207/S15324796ABM2601_01

Melani, A.S., \& Paleari, D. (2016). Maintaining control of chronic obstructive airway disease: Adherence to inhaled therapy and risks and benefits of switching devices. Journal of Chronic Obstructive Pulmonary Disease, 13(2), 241-250. doi:10.3109/15412555.2 015.1045972

Molimard, M., \& Colthorpe, P. (2015). Inhaler devices for chronic obstructive pulmonary disease: Insights from patients and healthcare practitioners. Journal of Aerosol Medicine And Pulmonary Drug Delivery, 28(3), 219-228. doi:10.1089/jamp.2014.1142

Pallant, J. (2010). SPSS survival manual: A step by step guide to data analysis using SPSS. Maidenhead, England: Open University Press/McGraw-Hill.

Pereira, M., \& Silva, N. (1999). Escala de adesão aos medicamentos. Avaliação Psicológica: Formas e Contextos, 6, 347-351.
Pothirat, C., Chaiwong, W., Phetsuk, N., Pisalthanapuna, S., Chetsadaphan, N., \& Choomuang, W. (2015). Evaluating inhaler use technique in COPD patients. International Journal Of Chronic Obstructive Pulmonary Disease, 10, 1291-1298. doi:10.2147/COPD. S85681

Price, D., Keininger, D. L., Viswanad, B., Gasser, M., Walda, S., \& Gutzwiller, F. S. (2018). Factors associated with appropriate inhaler use in patients with COPD: Lessons from the REAL survey. International Journal OfChronic Obstructive Pulmonary Disease, 13, 695-702. doi:10.2147/COPD.S149404

Riley, J., \& Krüger, P. (2017). Optimising inhaler technique in chronic obstructive pulmonary disease: A complex issue. British Journal Of Nursing, 26(7), 391-397. doi:10.12968/bjon.2017.26.7.391

Rocha, V. (2017). A teoria da autodeterminação e a dependência tabágica em adultos após síndroma coronária aguda: Um estudo longitudinal (Ph.D. Thesis). Faculdade de Psicologia e de Ciências da Educação da Universidade do Porto, Portugal.

Sriram, K. B., \& Percival, M. (2016). Suboptimal inhaler medication adherence and incorrect technique are common among chronic obstructive pulmonary disease patients. Chronic Respiratory Disease, 13(1), 13-22. doi:10.1177/1479972315606313 
